\title{
PNEUMONIA DUE TO PNEUMOCOCCUS TYPE XIV (COOPER) AND ITS TREATMENT WITH SPECIFIC ANTISERUM ${ }^{1,2}$
}

\author{
By JESSE G. M. BULLOWA \\ (From the Harlem Hospital Station of the Littauer Pneumonia Research Fund of New York \\ University and the Medical Service, Harlem Hospital (Department of Hospitals), and \\ the Bureau of Laboratories (Department of Health), New York City)
}

(Received for publication January 3, 1935)

Because of the anatomical similarity of the lesion in the lung, diseases caused by different types of pneumococci have been described together as a single disease. The difference in the severity of pneumonias due to different types of pneumococci was recognized in the monograph of Avery, Chickering, Cole and Dochez (1). Prior to studies made possible by the Cooper classification of the pneumococci, most physicians believed that the pneumonias due to pneumococci of Group IV (Avery) were less severe than the recognized Types I, II and III.

The specific types of pneumococci are serologically distinct though most of them cannot be distinguished by differences in colony form or cell morphology. They are distinguished by means of the specific reaction with antibodies produced in rabbits or horses. Our studies have now progressed to a point where the number of cases each due to a single type of pneumococcus is sufficiently numerous to warrant a tentative statement of the kind of clinical reaction or disease caused by certain of these types.

Types behave differently in age incidence, blood invasiveness, complications and severity of illness, and in the character of the consolidation as inferred from the physical signs and radiograms. In some instances the general picture may be so definite that the type of invading pneumococcus has occasionally been correctly suspected or guessed before an examination of the cultures had been made.

1 Read before the Section of Medicine, New York Academy of Medicine, October 16, 1934.

2 Our appreciation is expressed to loyal coworkers. Serum was produced through a grant from the Altman Foundation, Inc., and the children were studied, in part, through financial assistance from the Commonwealth Fund. The Metropolitan Life Insurance Company assisted this study. We are grateful to Miss Cooper for checking the correctness of typing, in cultures sent to her.
We are about to describe the pneumonias due to Pneumococcus Type XIV of whose origin Miss Cooper says :

"After the differentiation of Types IV to XIII, a number of strains hitherto unclassified were selected for the production of additional antisera (in rabbits) for typing, among which were strains isolated from:

Patrick Thompson: Age 39, Harlem Hospital, November 26, 1928, severe illness; recovered. Strain from positive blood culture November 28, 1928.

Catherine Murray: A child. Harlem Hospital. December 23, 1928. Died. Strain from positive blood culture December 23, 1928.

Clark: Age 23/4. Bellevue Hospital, January 5, 1929. Moderately severe illness; recovered. Strain from throat swab January 5, 1929."

"When agglutination tests were carried out with these antisera and the various stock strains, the three strains above mentioned were found to be similar and these, along with other strains agglutinated by these antisera, were termed Type XIV."

Frequency of occurrence. This study is principally based on our experience with 127 cases of pneumonia due to Pneumococcus Type XIV observed at Harlem Hospital in the lustrum from July 1,1928 to June 30,1933 . The adults (43 patients older than twelve years) were observed on our Pneumonia Service, and the children (85) on the Pediatric Service through the generous permission of Dr. Morris Gleich.

Pneumococcus Type XIV is one of the most frequent invaders of children, causing 16.1 per cent of the 547 pneumococcus pneumonias in our series. Among 2546 adults suffering from pneu- 
mococcus pneumonia it was the cause in 2.6 per cent. Raia, Plummer and Shultz (2) found Type $\mathrm{XIV}$ in 20 of 182 cases of pneumonia in children at Bellevue Hospital, with 10 per cent deaths; 15 females. Among 43 adults, 31 were males. This also occurs among children (among 85 children attacked, 46 were males) and even among the infants under one year of age; among 51 infants
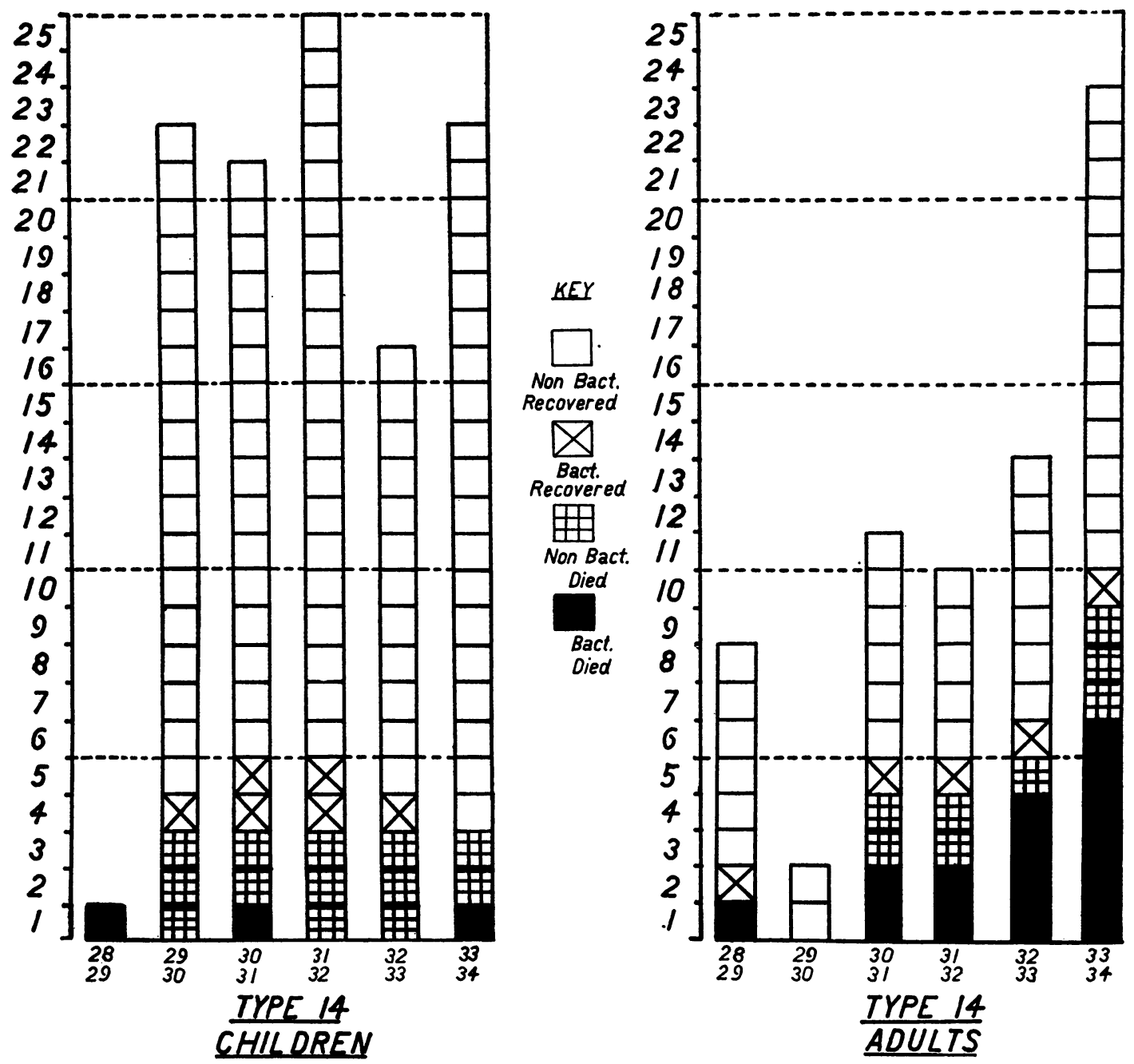

Fig. 1. Pneumonia Due to Pneumococcus Type XiV.

Annual incidence of cases and outcome in each of six years. Children and adults separately.

of the cases were in children under three years. Nemir (3) who continued their observations, had 68 cases of Type XIV among 276 children, with a mortality of 18 per cent in infants under two years. Kereszturi and Hauptmann (4), at the Fifth Avenue Hospital, found a 15 per cent incidence of Type XIV among children; they had 17 cases with 3 deaths ( 17 per cent).

Sex and age. Pneumococcus Type XIV, like other pneumococci, attacks many more males than attacked, 32 were males. Among children the pneumonias occurred most frequently in the first year. (See Figure 3.)

In Figure 2, which contrasts, in the five and one-half year period from July 1, 1928 to December 31,1933 , the frequency of Type I and Type $\mathrm{XIV}$ by year of age, it is shown that before puberty Pneumococcus Type I and Pneumococcus Type XIV are about equally frequent, and together they cause about 31.3 per cent of the 
pneumococcus pneumonias in children. There is a marked difference in their selection, however; whereas Type XIV causes one-fifth of the pneumococcus pneumonias during the first three years,
Among adults, Type XIV is increasing in frequency among our cases, as may be seen in the Figure 1 which presents the cases separately for each of six years. Last year there were 23 cases.

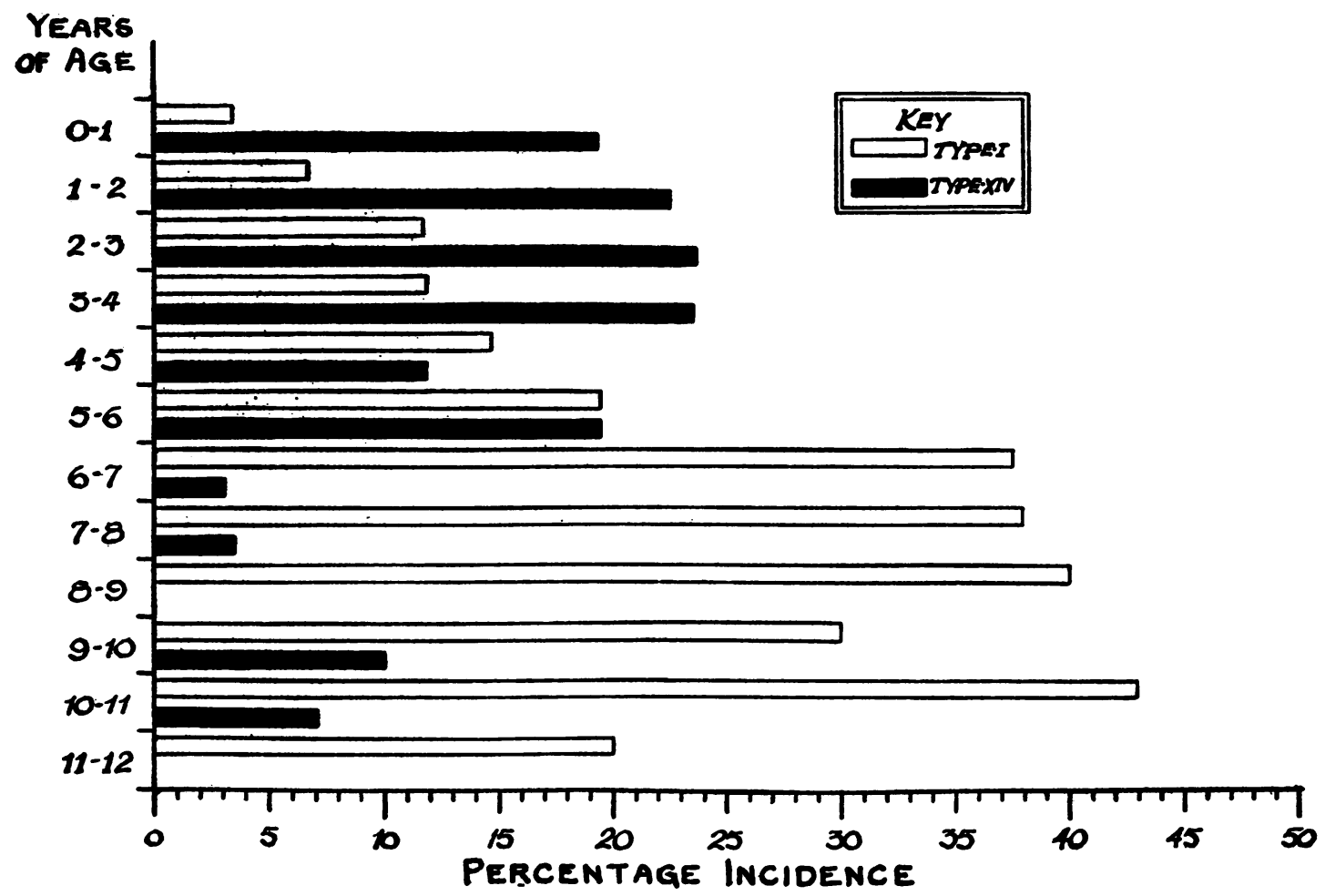

Fig. 2. Comparison of Percentage Incidence of Type I and Type XIV by Year of Age Among 547 Pneumococcus Pneumonias in Children.

July 1, 1928 to December 31, 1933.

after age six it occurs less frequently than Type I. The childhood mortality for Type XIV is much greater than for Type I. For Type I it is 6.4 per cent; for Type XIV, 16.1 per cent. Children of four or five years of age either meet new exposures in the street, the day nursery and the school, or have a changed susceptibility which latter fact may account for the difference in the organism causing the pneumonias. After infancy Type XIV surrenders its dominance to Type I though it does not yield its lead in fatality.

It is significant that our figures agree with the contemporaneous studies of Nemir (3) and Kereszturi and Hauptmann (4) in different sections of the city, and support Nemir's conclusion that Type XIV is the predominant type for infants, and Type $I$ the predominant type among older children.
In the lustrum 1928 to 1933, it produced a high mortality and was most frequently encountered in the fourth decade where it was especially fatal (Figure 4).

Anatomical form. Lobar pneumonia, as determined by localization of the consolidation in a single lobe or lobes (usually confirmed radiographically) was more frequently encountered in children than bronchopneumonia (37 among 51); this occurred even in infants under one year. Only three of the 17 instances of bronchopneumonia occurred after the first year (Figure 3 ). In adults all the cases were of lobar type. As seen in the radiogram, an entire lobe was usually involved and the shadows were not dense. The interlobar fissure was often sharply outlined on the side of the lesion.

Onset. The onset was not characteristic. In 
children, vomiting was frequently noted at the much higher incidence, 3 among 20 children (15 onset. Among 43 adults only three cases had

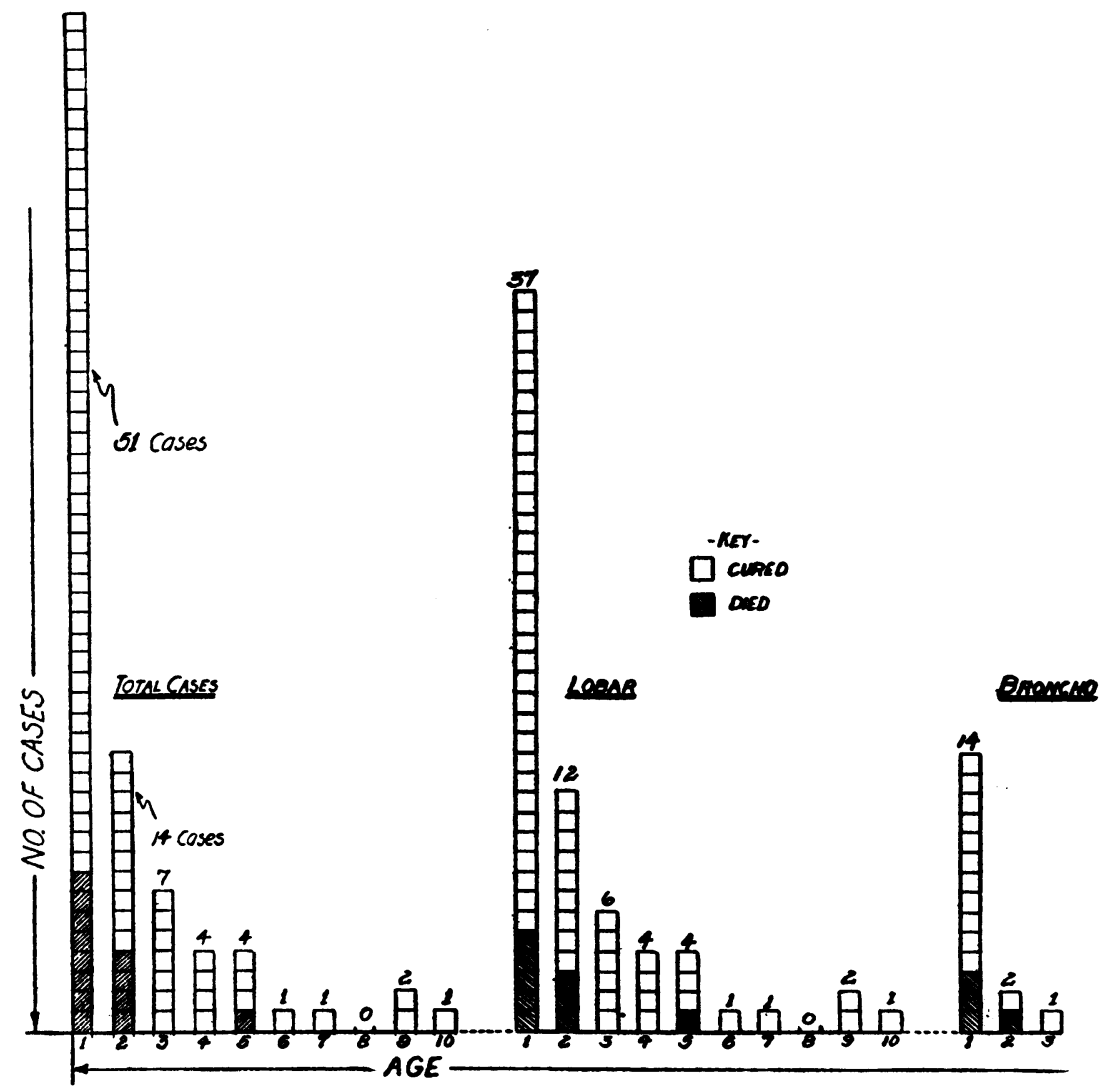

Fig. 3. Distribution of Age Incidence and Mortality.

Pneumococcus Pneumonias Type XIV (Cooper). Children. 1928-1933.

neither rigor nor chest pain at the onset. Rigor and chest pain ushered in the illness in 24 cases, pain in 15 and rigor in 1 . With the invasion, 29 cases had cough, 7 had vomiting, 7 had shortness of breath, 14 had headache and 20 fever. The onset was preceded by cold in the head in 8 cases, and by cough in 7 cases.

Pleuritic involvement. Pleuritic involvement as determined by $\mathrm{x}$-ray or physical signs was extremely frequent, occurring in 20 cases out of 85 children, and in 30 among 43 adults.

The occurrence of empyema in the adults (3 out of 43 cases with 3 deaths) is high. The incidence of empyema in children, in spite of the pleural involvement, was not high in our series or in that of Nemir. At Harlem Hospital there was one empyema among 85 cases, and at Bellevue Dr. Nemir reported one empyema among 68 children. Raia, Plummer and Shultz (2) found a

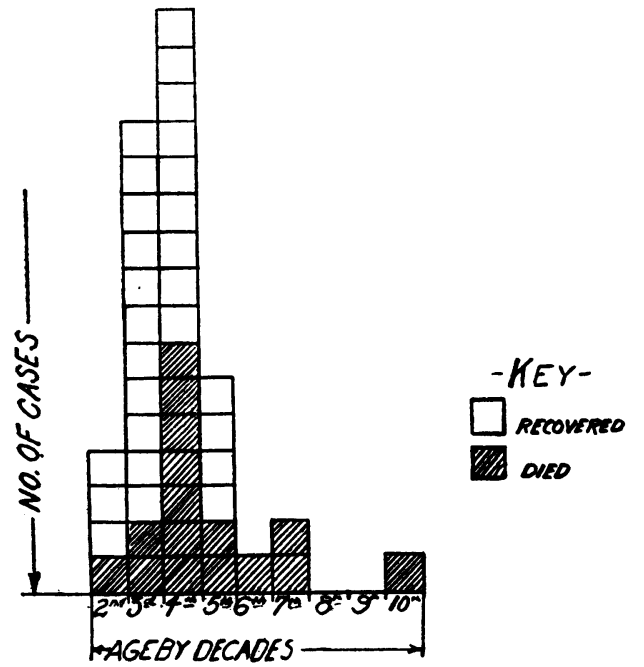

Fig. 4. Age and Mortality Distribution.

Pneumococcus Pneumonias Type XIV (Cooper). Adults. 1928-1933. 
the studies of Nemir, and Kereszturi and Hauptmann found 3 among 17 children (18 per cent) at the Fifth Avenue Hospital.

Lung suction. Because the determination of type was frequently accomplished by the routine technic of transthoracic lung suction performed on our service, we present the cases of pleurisy and empyema in a table (Table I) classified into more than twice as fatal in adults (69 per cent) as in children (28 per cent). The death rate in cases where the blood cultures were found to be negative is also greater in adults (23 per cent) than in children (14 per cent).

In some instances only broth cultures were positive or only a few colonies were present on the plates; these cases recovered spontaneously.

TABLE I

Lung suction in diagnosis of pneumococcus pneumonia Type XIV (Cooper) children and adults, 1928 to 1933

\begin{tabular}{|c|c|c|c|c|c|c|c|c|}
\hline & \multicolumn{2}{|c|}{$\begin{array}{l}\text { Positive lung } \\
\text { suction cases }\end{array}$} & \multicolumn{2}{|c|}{$\begin{array}{l}\text { Negative lung } \\
\text { suction cases }\end{array}$} & \multicolumn{2}{|c|}{$\begin{array}{l}\text { Total lung } \\
\text { suction cases }\end{array}$} & \multicolumn{2}{|c|}{$\begin{array}{l}\text { Non-lung } \\
\text { suction cases }\end{array}$} \\
\hline & Children & Adults & Children & Adults & Children & Adults & Children & Adults \\
\hline Total cases. & 26 & 13 & 13 & 6 & 39 & 19 & $13^{*}$ & $2 *$ \\
\hline $\begin{array}{l}\text { Total deaths } \ldots \ldots \ldots \ldots \ldots \ldots \ldots \ldots \\
\text { Percentage of deaths. } \ldots \ldots \ldots \ldots \ldots\end{array}$ & $\begin{array}{r}4 \\
15\end{array}$ & $\begin{array}{r}5 \\
38\end{array}$ & $\begin{array}{r}3 \\
23\end{array}$ & $\begin{array}{r}1 \\
17\end{array}$ & $\begin{array}{r}7 \\
18\end{array}$ & $\begin{array}{r}6 \\
32\end{array}$ & $\begin{aligned} 6 \\
13 \ddagger \\
18 t\end{aligned}$ & $\begin{array}{l}10 \\
42 \ddagger \\
45 \ddagger\end{array}$ \\
\hline $\begin{array}{l}\text { Cases with bacteremia ................ } \\
\text { Cases treated with serum......... } \\
\text { Cases first typed from lung suction .. }\end{array}$ & $\begin{array}{r}2 \\
10 \\
13\end{array}$ & $\begin{array}{l}5 \\
3 \\
8\end{array}$ & $\begin{array}{l}2 \\
2\end{array}$ & $\begin{array}{l}2 \\
0\end{array}$ & $\begin{array}{r}4 \\
12\end{array}$ & $\begin{array}{l}7 \\
3\end{array}$ & $\begin{array}{l}3 \\
1\end{array}$ & $\begin{array}{l}6 \\
3\end{array}$ \\
\hline
\end{tabular}

* Cases with low temperatures.

† Cases with high temperatures.

$\ddagger$ Based on both groups.

those which had been and those which had not been subjected to this procedure, with the fatalities for each group. The part that lung suction played in the typing is also shown. In half the cases the type was first determined in this way. The mortality was not increased by lung suction. It seems proper to reject from comparison those patients convalescent and with a low temperature by the time the result of the pharyngeal culture was returned, and in whom a lung suction was accordingly unnecessary for diagnosis and was not done.

Sputum. The sputum was studied in respect to character. It was noted that thick, prune juice and rusty, tenacious sputum was associated with an unfavorable outcome.

Blood count. Blood counts varied in no way from those in pneumonia of most other types.

Bacteremia. Bacteremia was found among 8 of the 85 children and was fatal twice. Thirteen among 43 adults had positive blood cultures and 9 of them died. The incidence of bacteremia was more than three times higher in adults (30 per cent) than in children (9 per cent). Its influence on mortality was very marked. Bacteremia was
In many cases, cultures were positive in broth only and colonies did not appear on the plates in later cultures. In some cases there was an increase in colonies which frequently became overwhelming in a short time. In one adult, M. L., the blood became sterile after 15,000 units of specific antiserum was administered. In one case there were many thousands of colonies for a number of days before death.

Specific immunity. The presence of immunity was tested by the presence of agglutinins by the stained slide technic. In this study it was found that in 12 patients (adults and children) in whom agglutinins were detected, none died; they may have appeared spontaneously, have been induced by the injections or have been passively transferred in them. Eight children who were given serum recovered although agglutinins were not demonstrated in their blood during the administration of serum or subsequently. One child died among 15 children who were not given serum and in whose blood agglutinins were not found. Among the adults, 2 patients died who had been given serum but in whose blood agglutinins were not found. Two of the 7 cases which did not re- 
veal agglutinins and which were not given antiserum, died. Agglutinins do not appear promptly in the blood after intramuscular injections of antiserum.

Associated organisms. Rarely, a pneumococcus of different type may be associated with Type XIV, or Type XIV may be present in the throat swab without pathologic significance. In charging responsibility we have given precedence to namely, Types IV, VIII and IX were encountered. In one instance, Staphylococcus albus was present and recovered postmortem from an abscess in the lung with this pneumococcus. In children, Dr. Nemir had an experience with Type XIX similar to ours. This type was found in the throat swab culture of a child but was not the cause of its illness. This was revealed by a subsequent empyema due to Type XIV and by the
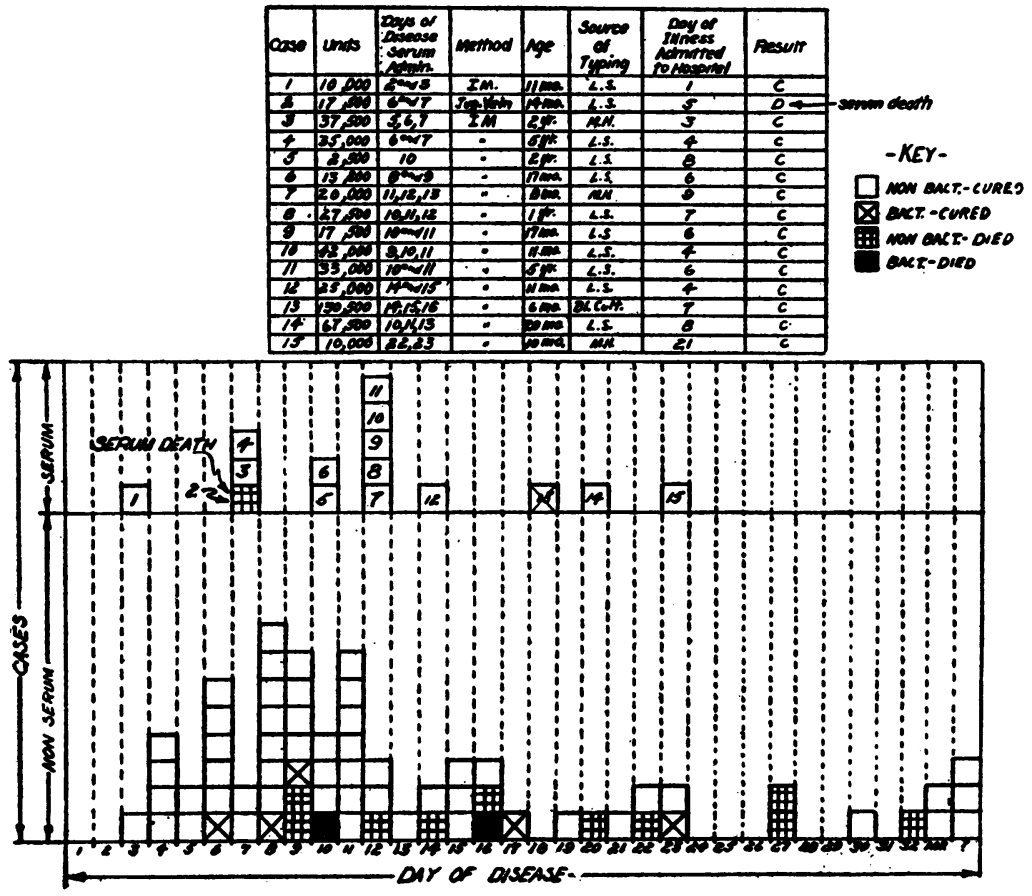

Fig. 5. Day of Termination and Outcome.

Pneumococcus Pneumonias Type XIV (Cooper). Serum and Nonserum. Children. 1928-1933. I.M. = intramuscular. C=cured. $\mathrm{D}=$ died. L.S. = lung suction. M.H. = mouse heart.

the organisms found in the patient's blood or aspirated from the lung through the thoracic wall. Pneumococcus Type XIV appearing in the mouse heart culture has been given precedence over an organism in the mouse peritoneum unless the other organism was more numerous in the peritoneum. The organisms which were associated or carried in patients who had pneumonia due to Pneumococcus Type XIV were Type I in three instances, Type VI, a frequent invader of the lungs of children and the sinuses of adults, and Type XIX, another frequent invader of the air passages and lungs of children, which occurred twice. In three instances, other pneumococci, failure of Type XIX serum to change the course of the illness.

Duration. The duration of the disease may be seen by a study of Figures 5 and 6 . In the figure the day of termination and the outcome are given for cases treated with and without antiserum. The average (median) duration among children was 12 days, and among adults 8 days. Among children the illness in the fatal cases lasted, on the average, 16 days; the mean duration in the fatal cases was 7 days. Among the adults, the mean duration was eight days among those who recovered and seven days among those who died. In one case which recovered the illness lasted 
seventeen days, and one patient died on the eighteenth day.

Termination. Among 64 adult cases (1928 to 1934) 40 recovered; of these, 28 (44 per cent) terminated by lysis, and 12 ( 19 per cent) by crisis. Among 83 children (1928 to 1933) 15 (18 per cent) terminated by crisis, 53 ( 66 per cent) by lysis, and 13 died.

Complications, associated diseases and menacing symptoms. The great incidence of menin- times. Once, Pneumococcus Type XIV was cultured; two of the twelve cases not cultured died. Acute gastroenteritis occurred once in a fatal case. Acute tonsillitis and a Vincent's stomatitis occurred in children who recovered. Rickets was present in four children. Two of the three infants who were greatly malnourished died. Four children who showed marked anemia and received whole blood intramuscularly recovered.

A large number of cases required oxygen, 47

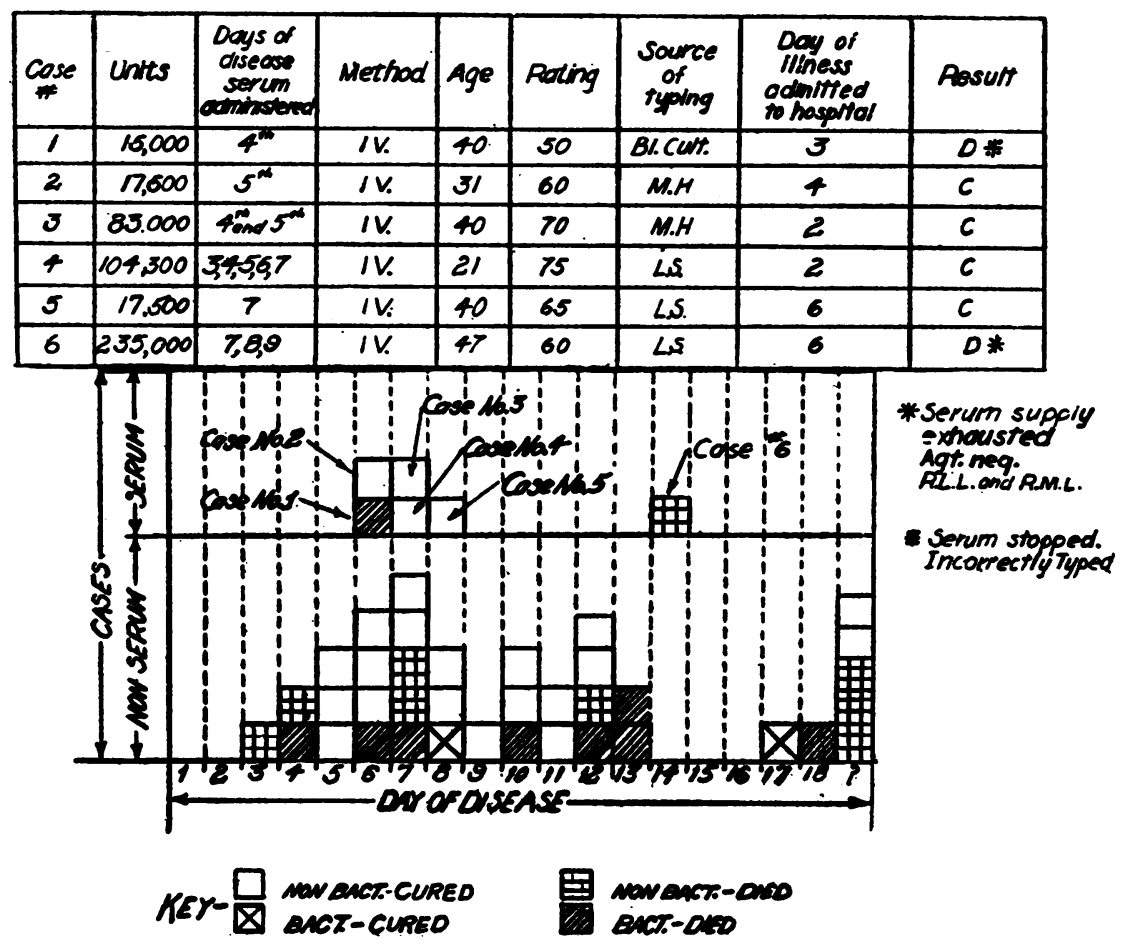

Fig. 6. Day of Termination and Outcome.

Pneumococcus Pneumonias Type XIV (Cooper). Serum and non-serum. Adults. 1928-1933. I.V.= intravenous. M.H. = mouse heart. L.S. =lung suction. $\mathrm{C}=$ cured. $\mathrm{D}=$ died.

gitis among the children ( 3 among 85 cases) is noteworthy. When pleurisy was present it added to the gravity of the disease. Four of 20 children, and nine among 30 adults, who had this symptom died. Pericarditis was fatal whenever it occurred, once in a child and three times in adults. Pyarthrosis of the shoulder occurred once. An associated fatal $B$. influenzae meningitis occurred once. Pulmonary gangrene resulting from an associated Staphylococcus albus lung abscess was found postmortem in one instance. Among the children, otitis media occurred fifteen out of 85 ( 56 per cent) among the children, and 18 among 43 adults ( 42 per cent). Delirium and distention occurred frequently. Seven of the 9 delirious adults died. Three fatal cases had required restraints. Two of the fatal delirious patients had a bacteremia. Five children were distended; three of these had an associated anoxia, and only these three died. Nine of the 15 adults who were distended were also anoxic; five of the 9 who were anoxic had a positive blood culture; these and three others died. Those without anoxia recovered. Icterus occurred once in a fatal 
case. Severe hiccough occurred once, with ultimate recovery. Fatal pulmonary edema was, as usual, frequently associated with bacteremia. The temperature, pulse and respiration were no different than in similar severe cases among other types.

In contrast with its virulence for human beings, it is significant that none of the cultures of Type XIV from children or adults sent to Miss Cooper from our service or from Bellevue Hospital have so far been sufficiently virulent for white mice to permit titration of the potency of therapeutic sera by protection tests.

One thousand to one hundred thousand organisms are required for the minimum lethal doses of the Type XIV strains thus far examined, while two or three organisms of the strains of other types used as test cultures in protection tests are fatal for mice.

Electrocardiographic changes. We shall report elsewhere, with Lowen, the electrocardiographic findings in 140 patients suffering from pneumonias of different types of pneumococci. Only two patients, both with pneumonia due to Pneumococcus Type XIV, developed, during convalescence, coving of the $T$ wave in Leads $I$ and II which was indistinguishable from that found in coronary artery disease.

Description of disease produced by Pneumococcus Type XIV. We may sum up our observations by describing the pneumococcus pneumonias due to Pneumococcus Type XIV as a disease especially common in very young children, producing usually a lobar pneumonia, even in infants. Among adults it frequently invades the blood, causing a severe disease with pleurisy, pericarditis and meningitis. In children it is of prolonged duration and, at times, it is rather tardy in the production of agglutinins (demonstrable by the slide technic). The production of the agglutinins is, as in other types, usually of good omen.

Serum. In view of the very great fatality and blood invasiveness of this disease, it seemed desirable to attempt to produce a therapeutic antiserum. This was produced under the direction of Dr. Park at the Bureau of Laboratories of the Department of Health, with financial assistance from the Altman Foundation and the Littauer Fund. Since the beginning in April, 1929, of the attempt to produce antisera for Type XIV, twelve horses have been allotted to this purpose. The difficulty in obtaining antiserum is exemplified by the fact that two of the horses died after having been injected for four months, one after five months and one after ten months. No serum suitable for therapeutic use was obtained from these horses. Suitable serum was obtained from two horses which were injected for a period of ten months and from two others injected for seventeen months. Four horses are being injected at the present time. Three have been injected for ten months and the injections of one horse have just been started. Serum for therapeutic use is being collected from two of the horses.

TABLE II

Serum treatment in adults and children, Pneumococcus Type XIV (Cooper)

\begin{tabular}{|c|c|c|c|c|c|c|}
\hline \multirow{2}{*}{$\begin{array}{c}\text { From } \\
1928 \text { to } 1933\end{array}$} & \multicolumn{3}{|c|}{ Non-serum } & \multicolumn{3}{|c|}{ Serum } \\
\hline & Cases & Deaths & Per cent & Cases & Deaths & Per cent \\
\hline Adults (43) . . & $\begin{array}{l}37 \\
12^{*}\end{array}$ & $\begin{array}{l}14 \\
8^{*}\end{array}$ & $\begin{array}{l}38 \\
67^{*}\end{array}$ & $\begin{array}{l}6 \ddagger \\
1 *\end{array}$ & $\begin{array}{l}2 \\
1 *\end{array}$ & $\begin{array}{r}33 \\
100\end{array}$ \\
\hline Children (85).. & 70 & 12 & $\begin{array}{l}17 \\
29 *\end{array}$ & 15 & $\begin{array}{l}1 \\
0^{*}\end{array}$ & $\begin{array}{l}7 \\
0^{*}\end{array}$ \\
\hline Total (128)... & $\begin{array}{c}107 \\
19^{*}\end{array}$ & $\begin{array}{l}26 \\
10^{*}\end{array}$ & $\begin{array}{l}24 \\
53^{*}\end{array}$ & 21 & $\begin{array}{l}3 \\
1^{*}\end{array}$ & $\begin{array}{l}14 \\
50^{*}\end{array}$ \\
\hline \multicolumn{7}{|l|}{$\begin{array}{l}\text { Children from } \\
\text { July } 1,1928 \\
\text { to } \\
\text { July } 1,1934\end{array}$} \\
\hline $\begin{array}{c}\text { Under three } \\
\text { years (82).. }\end{array}$ & $\begin{array}{c}63 \\
5^{*}\end{array}$ & 12 & $\begin{array}{l}19 \\
40^{*}\end{array}$ & $\begin{array}{c}19 \\
2 *\end{array}$ & $\begin{array}{l}2 \\
1^{*}\end{array}$ & $\begin{array}{l}11 \\
50^{*}\end{array}$ \\
\hline $\begin{array}{l}\text { Birth to } 12 \\
\text { months }(36)\end{array}$ & 27 & $\begin{array}{l}5 \\
0^{*}\end{array}$ & $\begin{array}{c}19 \\
0^{*}\end{array}$ & $\begin{array}{l}9 \\
1 *\end{array}$ & $\begin{array}{l}0 \\
0^{*}\end{array}$ & $\begin{array}{l}0 \\
0^{*}\end{array}$ \\
\hline $\begin{array}{l}\text { Three years } \\
\text { and over (25) }\end{array}$ & 20 & $\begin{array}{l}1 \\
0^{*}\end{array}$ & $\begin{array}{l}5 \\
0^{*}\end{array}$ & $\begin{array}{l}5 \\
0^{*}\end{array}$ & $\begin{array}{l}1 \\
0^{*}\end{array}$ & $\stackrel{20}{0^{*}}$ \\
\hline
\end{tabular}

* Asterisk indicates cases with positive blood culture. $\ddagger$ Including two incompletely treated because of lack of serum-fatal. Only one case (not included) was treated in 1934 -recovered.

Eleven preparations of concentrated refined antiserum have been prepared. The method of concentration used was the same as that used for Type I antiserum.

Pending the discovery of a more virulent 
strain, the potencies of the Type XIV antisera are tested by titrations of their precipitin and agglutinin content and are calculated in comparison with antisera for other types which have been more completely tested. Experience with this antiserum has not been sufficiently great to permit final conclusions as to its value. It has been possible to terminate the disease in some of the cases by intramuscular injections. The failures there were no deaths. In adults, 4 cases adequately treated, recovered. Two insufficiently treated (in one case because the supply of serum was exhausted) died.

The statistics suggest that treatment by antiserum was helpful. Termination of disease occurred after the administration of sufficient antiserum to effect humoral immunity, as shown by the demonstration of agglutinins in the blood.

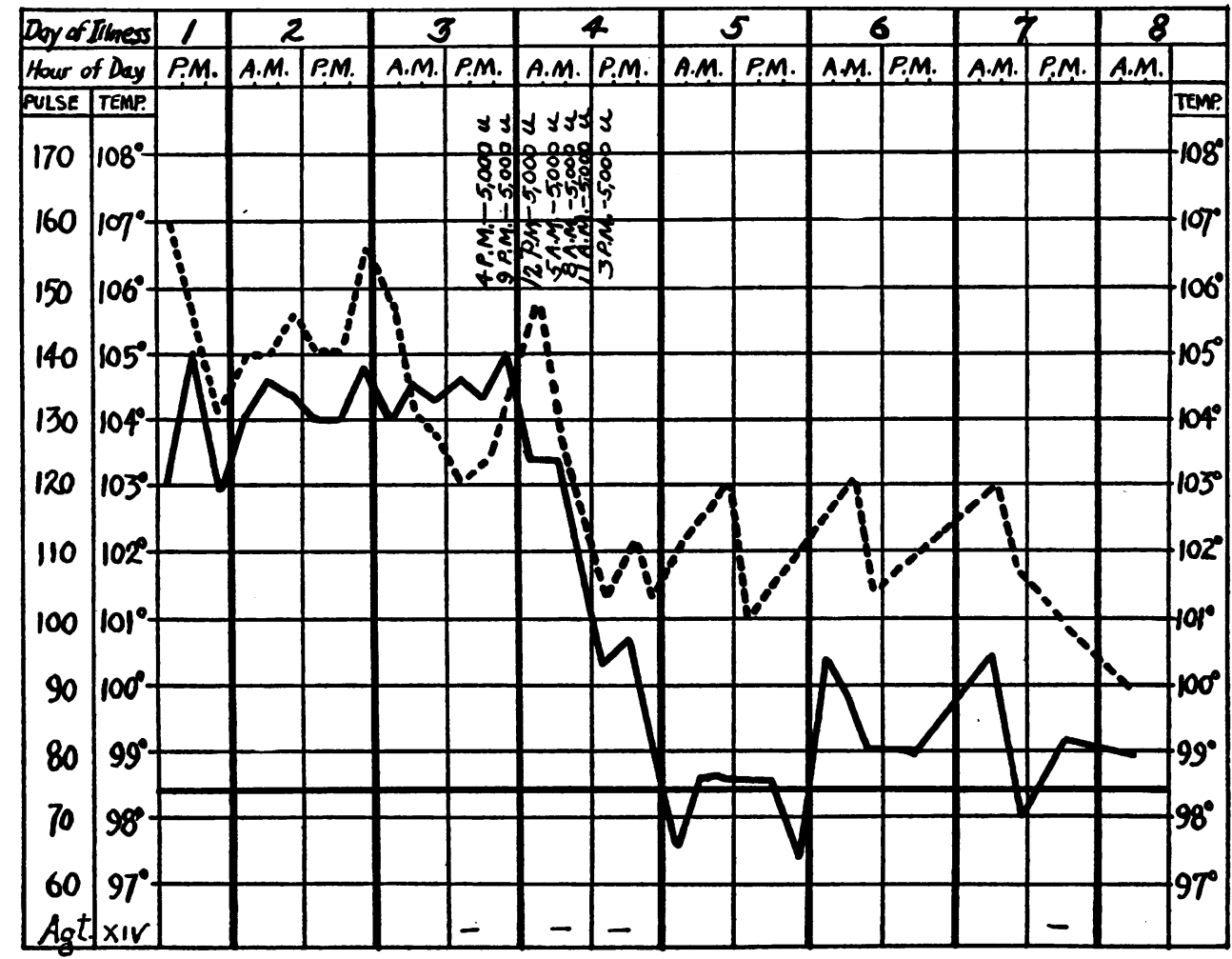

Fig. 7. Case M. T. Female, 5 Years of Age.

Sputum, Type XIV, lung suction Type XIV, blood culture negative. X-ray, pneumonia right lower lobe. Distended. $\mathrm{O}_{2}$ per nasal catheter. Agglutination remained negative. Solid line, temperature; broken line, pulse rate.

appear to have been due to insufficient serum. When little serum was available the sickest cases were chosen; at other times alternate cases were given antiserum. The results are seen in Table II. In children under three, there were 63 cases with 12 deaths (19 per cent) in the controls; of the 19 who were treated, there were 2 deaths (11 per cent). There were 27 cases under a year who did not receive antiserum; 5 died, a mortality of 19 per cent. In the same age group, 9 cases received antiserum in the thighs or buttocks and
The following case histories illustrate either the normal course of the disease or reveal the fall of temperature which occurred, in most cases, at the same time that agglutinins appeared when antiserum was administered either early or later in the disease.

\section{CHILDREN}

1. H. G., female, $31 / 2$ years. Lobar pneumonia, left lower lobe. The temperature was elevated, $103^{\circ}$ to $105^{\circ} \mathrm{F}$., with a rapid pulse (120 to 140$)$ and accelerated respiration (40 to 60 ) for a week 
prior to admission. In the oxygen chamber the fever continued, with a crisis of the temperature on the 16th day and of the pulse on the 18th day.

2. M. T., female, 5 years, lobar pneumonia, right lower lobe; distended. Temperature $104^{\circ}$ to $105^{\circ} \mathrm{F}$., pulse 120 to 170 , and respirations 40 to 50 . Type obtained by lung suction. Critical termination of fever came on the fourth day after administration of seven injections each 5000 units of serum into phlebitis left tibial veins developed on eleventh day. Death occurred on twelfth day.

4. F. F., male, 35. Bacteremia. Extensive consolidation was present. Death on 5th day. No agglutinins appeared.

5. M. P., female, 40. Right lower lobe involved. Temperature $104^{\circ} \mathrm{F}$., pulse 120 . There was a critical termination after three intravenous doses of 5000 units of antiserum, four hours apart, on the sixth

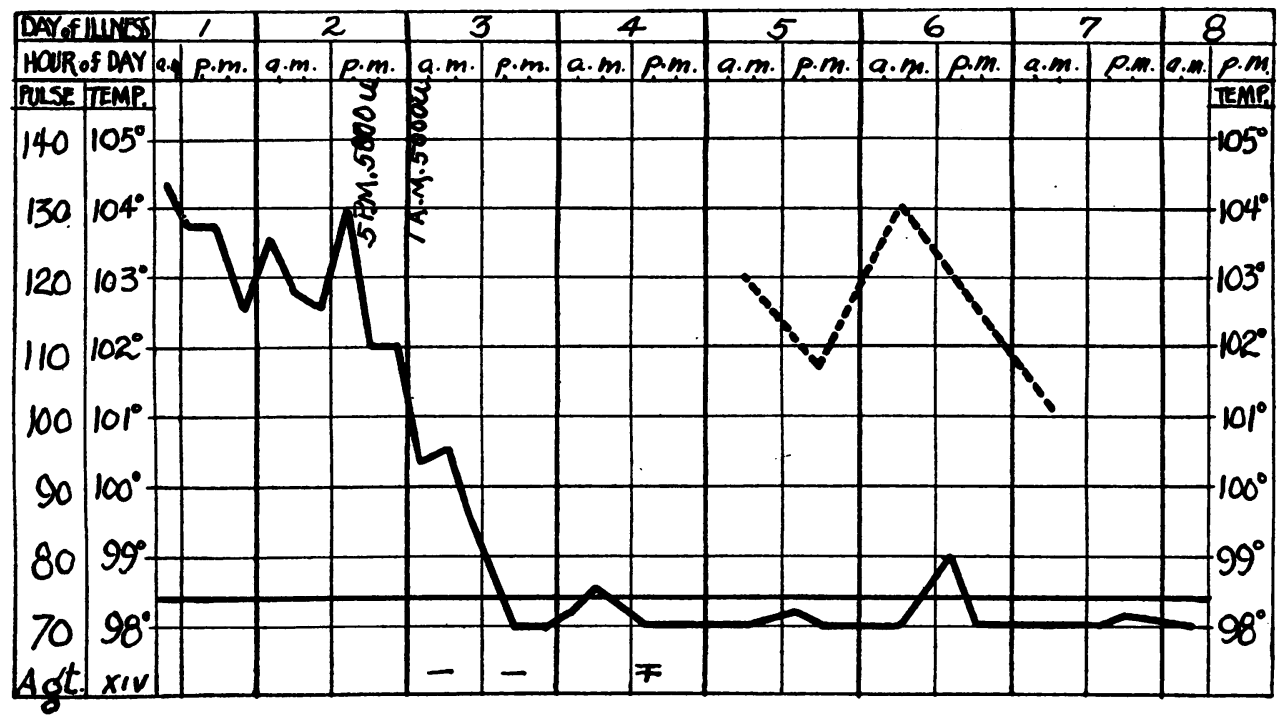

Fig. 8. Case N. S. Female, Age 11 Months.

Marasmus. $\mathrm{O}_{2}$ per nasal catheter. Radiograph negative. Fluoroscopy-increased hilum shadow and slight opacity left base. Lung suction Pneumococcus Type XIV, laryngeal culture Type XIV, blood culture negative. Solid line, temperature; broken line, pulse rate.

the buttocks at three hour intervals. No agglutinins appeared. (See Figure 7.)

3. N. S., female, 11 months, marasmus. Admitted on the first day. Treated on the second day. Temperature $102.6^{\circ}$ to $104^{\circ} \mathrm{F}$. Respirations 64 . Crisis came on the third day, with agglutination $\mp$ on the fourth day. Type was obtained by lung suction. Slight opacity was noted with fluoroscope. This child received two intramuscular injections (5000 units) twelve hours apart on second and third day. (See Figure 8.)

\section{ADULTS}

1. E. C., male, 30. Right upper lobe involved. Agglutination appeared on the fifth day. Temperature became normal on sixth day. Type obtained by lung suction. No serum given.

2. M. N., female, 37. Left lower lobe. Agglutination evident on seventh day; became stronger on ninth day, when the temperature fell to normal.

3. F. H., male, 45. Temperature had fallen before admission. Strong agglutination was present on tenth day. Auricular fibrillation, and thrombo- day. Agglutinins were not demonstrated. Pneumococcus Type XIV was recovered from sputum and lung suction.

The death of one child was due to anaphylactic shock from the administration of a $5 \mathrm{cc}$. dose of antiserum given into the jugular vein. We are satisfied that this is an excessive initial dose of serum by vein for children. We now limit the initial intravenous dose of serum in children to $1 \mathrm{cc}$. or we use it intramuscularly. In adults the antiserum for Type XIV pneumococci seemed to produce more reactions when given intravenously than antiserum for other types with which we are now making observations.

In view of the frequency, the prolonged duration, the relatively high mortality rate (especially in the bacteremias among adults) of Type XIV infections, and the suggestive results achieved in treatment by specific antiserum, it seems impor- 
tant to produce and administer antiserum and to attempt to increase its potency and to endeavor to refine it.

\section{SUM MARY}

To summarize, Pneumococcus Type XIV is a virulent organism for human beings, selecting by preference infants and young children, in whom the pneumonias are usually of long duration. It has increased in frequency among adults admitted to our service; in these subjects it is especially prone to invade the blood and to prove fatal. It apparently involves the pleurae pericardium and meninges with greater frequency than many other types of pneumococci. Upon recovery, agglutinins appear. Protective antibodies, including agglutinins, can be transferred from horses injected with this pneumococcus. In many of our cases there was evidence that when suffcient antiserum was given there occurred defervescence and earlier recovery.

\section{BIBLIOGRAPHY}

1. Avery, Oswald T., Chickering, H. T., Cole, Rufus, and Dochez, A. R., Acute lobar pneumonia; prevention and serum treatment. Monograph Number 7, Rockefeller Institute for Medical Research, New York, 1917.

2. Raia, Antoinette, Plummer, Norman, and Shultz, Selma, New types of pneumococci in the pneumonias of children. Am. J. Dis. Child., 1931, 42, 57.

3. Nemir, Rosa Lee, The treatment of pneumonia in infants and children with antipneumococcus serum. J. Pediat., 1933, 3, 827.

4. Kereszturi, Camille, and Hauptmann, David, The serum treatment of pneumonia in children. J. Pediat., 1934, 4, 331. 